\title{
INVESTIGATION AND IDENTIFICATION OF MURAL PAINTINGS' MATERIALS AND TECHNIQUES IN AIN EL-LEBEKHA, EGYPT- PART ONE
}

\author{
Abdel Aal, Sh. \\ Conservation dept., Faculty of Archaeology, Fayoum Univ., Fayoum, Egypt \\ E-mail:smm00@fayoum.edu.eg
}

\begin{abstract}
The present study aims to investigate and identify the layers, components, and painting techniques of a mural painting in Ain el-Lebekha Temple located in Kharga Oasis, the capital of the New Valley Governorate, about $200 \mathrm{~km}$ to the Nile valley and $232 \mathrm{~km}$ to the south of Asyut city, forming a depression of $160 \mathrm{~km}$ long and $80 \mathrm{~km}$ wide. Archaeological and historical references pointed out that Ain el-Lebekha dates back to the Roman period between the $2^{\text {nd }}$ and $5^{\text {th }}$ centuries AD. Multi analytical and investigation studies were done to identify and define the compositions, techniques, and components, and state of the mural painting layers in Ain el-Lebekha Temple. Moreover, the investigations and examinations with the optical microscope, polarizing microscope, and scanning electron microscope were used to show the state, number and technique of the surfaces and painting layers. XRD, FTIR, and SEM-EDS analytical methods were used to identify the compositions of the mural painting layers and ground layers. They illustrated that calcite and quartz were used in the ground layer, hematite in the red pigment paint, and the Arabic gum as an organic medium in the painting process. The obtained results will enrich our knowledge about mural paintings and materials in an important archaeological site of the Greco-Roman art in Egypt to support the restoration plan.
\end{abstract}

Keywords: Ain el-Lebekha, Temple, Greco-Roman, Mural paintings, Pigments, Deterioration

\section{Introduction}

Ain el-Lebekha Temple was the most important site in the sixth dynasty since 2420 BC. Its period of prosperity lasted to the first Roman era, as well as and the rule of the Persians and Greeks that established great historical evidence, including temples, statues, and terraces [1-3]. The site dates back to the $2^{\text {nd }}$ and $5^{\text {th }}$ centuries AD. It is about $4 \mathrm{~km}$ from north to south and about $1.5 \mathrm{~km}$ from east to west. It is located on a high hill $43 \mathrm{~km}$ to the north of Kharga city and $300 \mathrm{~km}$ to Cairo. It is surrounded by a mountain range. It was referred to as the mulberry tree, which had been present in the region since ancient times. It contains Pharaonic and Roman archaeological rem- ains, fig. (1) [4-6]. Ain el-Lebekha includes a large collection of archaeological buildings and elements. It is one of the most important discovered temples in Kharga Oasis because with a distinctive collection of mural paintings that reflect a chapter of the Egyptian history. Unfortunately, these paintings and drawings have been exposed to different deterioration factors that caused a loss of the painting layers and pigments [7-10]. The study aimed to use a set of scientific analyses to describe and identify the mural paintings' layers, support, as well as the preparation ground layers, number, and current condition. These analyses help characterize pigment materials, quality, condition, and deterioration. Examinations and analyses 
were carried out using a set of modern scientific analysis methods, including microscopic investigation, XRD, SEMEDS, and FTIR, which provided important information about the nature of materials used in the layers of mural paintings, preparation grounds, pigments materials, organic binder, and current state $[11,12]$. $\mathrm{X}$-ray diffraction (XRD) is one of the most important analytical methods in defining the components of the mural paintings, the materials involved in the structure of both the preparation grounds and the plaster layers, and the pigment materials. XRD plays an important role in the analysis of archaeological materials, in general, and murals, in particular. Furthermore, the scanning electron microscopy (SEM) has played a significant role in the analysis of inorganic trace elements, including the pigments, the components of the painting layers, as well as other inor- ganic materials used. X-ray fluorescence (XRF) has an important role in the identification of the adobe brick (mud brick) as support of mural painting in Ain elLebekha Temple [13-15]. For the identification and characterization of the organic binder in mural paintings, FTIR was used because it is the most important method to provide information about the nature of the organic binder. The analysis was done to define the quality and nature of the organic medium based on the infrared absorption method [16-19]. To identify the number of layers, thickness, condition, and state of the surface, the optical microscope was adopted because of its great importance in the examination of mural paintings and their different layers, providing some important information about the nature of the chromatic change to the painted layer $[20,21]$.
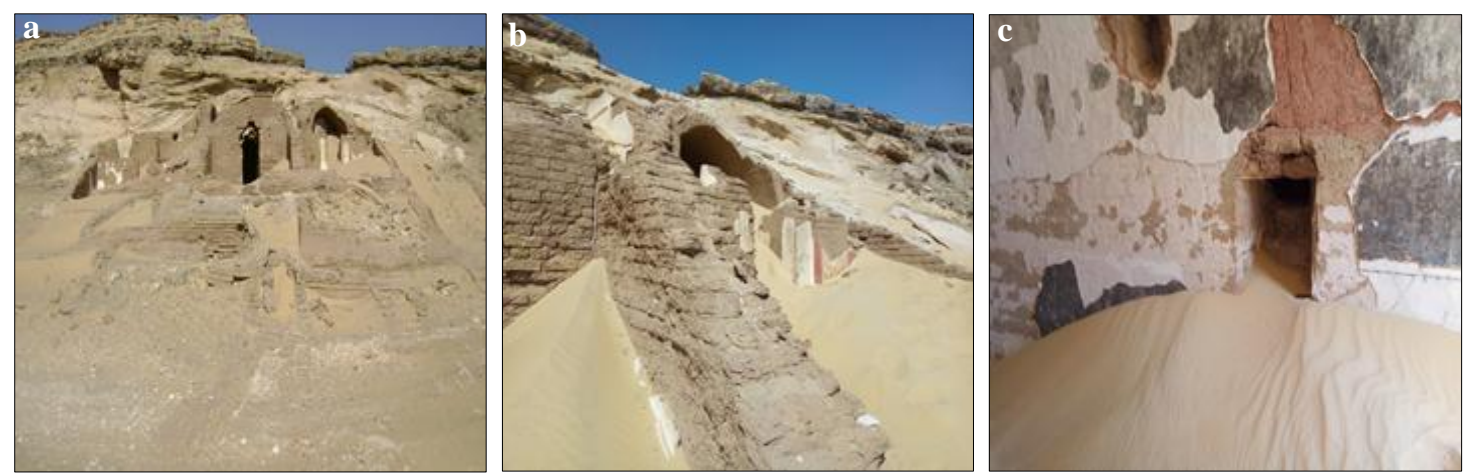

Figure (1) Shows the mural paintings residues from Ain el-Lebekha site

\section{Materials and Methods}

\subsection{Materials}

The collected samples from Ain el-

Lebekha site included the support of the

\subsection{Microscopic investigation}

The examination of mural painting samples using optical microscopy is a great importance examination because it provides valuable information about the nature, current state, number, thickness, and deterioration of each layer, as

\subsection{X-ray diffraction analysis (XRD)}

Different samples of mural paintings (the plaster layer and the painted materials) were prepared [26-29]. XRD device model Analytical Empyrean model 202964 at Beni Suef Univ. was used. The following conditions were set $(\mathrm{P} / 1840$ with $\mathrm{CU}$ Anode Material, operating system of copper radiation $1.54060^{\circ}$ at $25^{\circ} \mathrm{C}, 30 \mathrm{~mA}$, paintings, ground layers, plasters, and pigment materials.

well as the condition of the colored surface and the size of the pigment granules $[22,23]$. Prepared cross-sections were investigated by the wild MRI stereomicroscope, provided by the Olympus BX51 optical microscope [24,25].

Scan Step Time 0.5000, in the range of start position [2Th.] 5.0200 and end position [2Th.] 79.9800, a minimum step size of 2Theta:0.0001; a minimum step size Omega: 0.0001, The Regaco unit operated at $25 \mathrm{kV}, 30 \mathrm{~mA}$ for 30 minutes as a fixed time). 


\subsection{Scanning electron microscopy-energy dispersive $x$-ray analysis (SEM- EDX)}

The layers of the murals were examined using SEM, and the plaster layer and the preparation ground were examined using Philips Xl 30 Environmental Scanning Electron Microscope (ESEM) for characterizing the morphological features of the material. The analytical conditions were $30 \mathrm{Kv}$ and accelerating voltages was 1-2-mm beam diameter and 60-120-s

counting times. Minimum detectable weight concentration was from 0.1 to $1 \mathrm{wt} \%, \mathrm{P}$ precision well below $1 \%$, the relative accuracy of quantitative result 2-10\% for elements $Z>9$ (f) and 10-20\% for the light elements B, C, N, O, and F [30,31]. In addition, EDX analysis was performed for defining the chemical composition of the investigated samples.

\subsection{Fourier-transforms infrared spectroscopy (FTIR)}

Analysis of the organic binder of the mural painting layer was done using an infrared absorption pattern (FTIR). The study was conducted using the Perkin Elmer Spectrum. The measurements and

operating system were done in the region of $4000-400 \mathrm{~cm}^{-1}$ to define the type of the organic medium by identifying the organic functional groups of the organic materials [32-34].

\section{Results}

\subsection{Microscopic examination results}

Microscopic examination images showed the extent of deterioration in the components and layers of the mural paintings. The samples had a severe drought, as shown by a large number of accurate explanations of the preparation and the separation of the painting layer of the surface. The use of multi-layers for the preparation of murals showed the rough preparation ground with large sand grains, the soft preparation layer, followed by the painted layer. In addition, the painting layer suffered from severe drought noticed in its separation from the plaster layer. The images illustrated many aspects of damage, such as weak areas in the structure of

the murals that appeared weak and dry, cracks, and separations, fig. (2-a). The examination showed that all of the painting processes were done using a few pigment materials suggested by the thickness of the painted layer, which looks fragile and thin. It is also apparent that the chromatic layer is an unorganized layer, which is attributed to the unevenness of the surface and the plaster layer. Through the examination of the various samples, the extent of damage reached by the layers of the murals and the extent of the drought suffered by it, resulting in the separation of the painted layer from the surface and splits up, fig. (2-b).
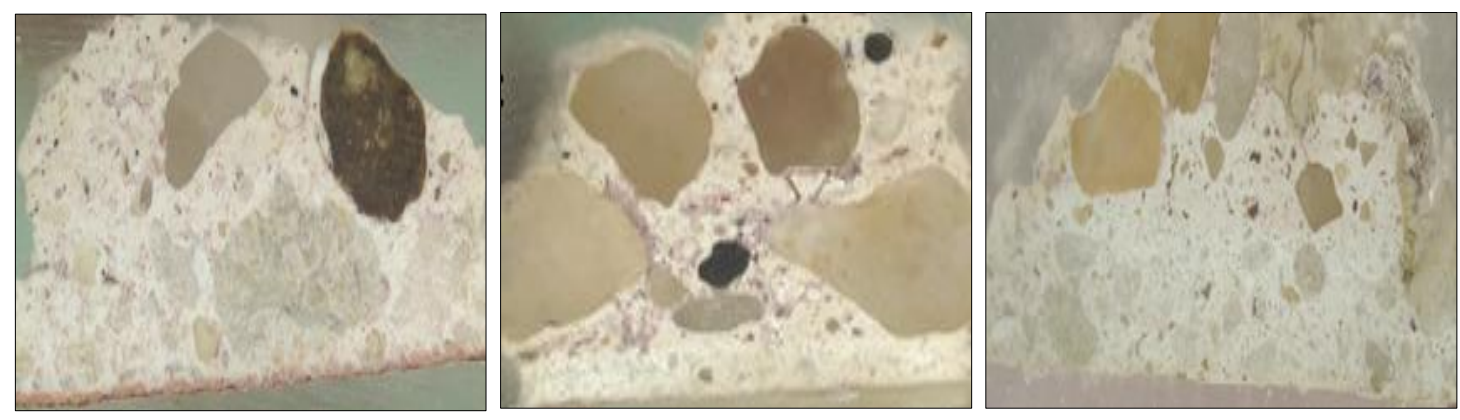

Figure (2) shows a cross-section of the painting samples using the optical microscope that indicated the extent of the mural layers' damages and drought that caused the separation of the painting layer

\subsection{XRD analysis results}

XRD results showed that the rough layer consisted of silicon dioxide $\mathrm{SiO}_{2}$ (quartz), calcium carbonate $\mathrm{CaCO}_{3}$ (calcite), and a small amount of calcium sulfate 
$\mathrm{CaSO}_{4}$ (gypsum). The analysis of the soft preparation layers showed the same components with different parentage. Furthermore, the results of the analysis of the white layer (plaster) showed calcium carbonate $\mathrm{CaCO}_{3}$, fig. (3-a,b,c). On the other hand, XRD analysis of painting layers (black, green, white and yellow pigments) showed that the red pigment sample was hematite $\mathrm{Fe}_{2} \mathrm{O}_{3}$; the main component of the red color. Black carbon was the main ingredient of the black pigments. The results of the analysis showed that calcium carbonate in the form of calcite was the main component of the white pigment, while the light yellow pigment was due to a mixture of goethite $\mathrm{FeO} \mathrm{OH}$ and calcium carbonate $\mathrm{CaCO}_{3}$. The green color was caused by copper chloride $\mathrm{CuCl}$ as a coloring material of the green pigment with calcium carbonate that reduced the color degree, fig. (3-d,e,f,g,h). XRD results of the support sample showed adobe (mud brick) composed of quartz $\mathrm{SiO}_{2}$, calcite $\mathrm{CaCO}_{3}$, sodium chloride $\mathrm{NaCl}$, and some clay minerals. The chemical analytical results of clay minerals carried out in the Raw Building Materials and Processing Technology Research Institute, Egypt indicated that the first clay mineral is kaolinite $\left[\mathrm{Al}_{2} \mathrm{Si}_{2} \mathrm{O}_{5}(\mathrm{OH})_{4}\right]$ that has a low shrinkswell capacity and a low cation-exchange capacity almost (1-15 meq/ $100 \mathrm{~g})$. It is a soft, earthy, and white color (dioctahedral phyllosilicate clay), produced by the chemical weathering of aluminum silicates, such as feldspar. The second is Illite $\left[\left(\mathrm{K}, \mathrm{H}_{3} \mathrm{O}\right)(\mathrm{Al}, \mathrm{Mg}, \mathrm{Fe})_{2}(\mathrm{Si}, \mathrm{Al})_{4} \mathrm{O}_{10}\left[(\mathrm{OH})_{2}\right.\right.$, $\left.\left(\mathrm{H}_{2} \mathrm{O}\right)\right]$. illite is one of the main clay phases that mainly consist of feldspars and quartz. The third clay mineral is montmorillonite $\left[(\mathrm{Na}, \mathrm{Ca})_{0.33}(\mathrm{Al}, \mathrm{Mg})_{2}\right.$ $\left.\left(\mathrm{Si}_{4} \mathrm{O}_{10}\right)(\mathrm{OH})_{2} \cdot n \mathrm{H}_{2} \mathrm{O}\right]$. It is a very soft phyllosilicate group of minerals. It is a member of the smectite group fig. (3-i)
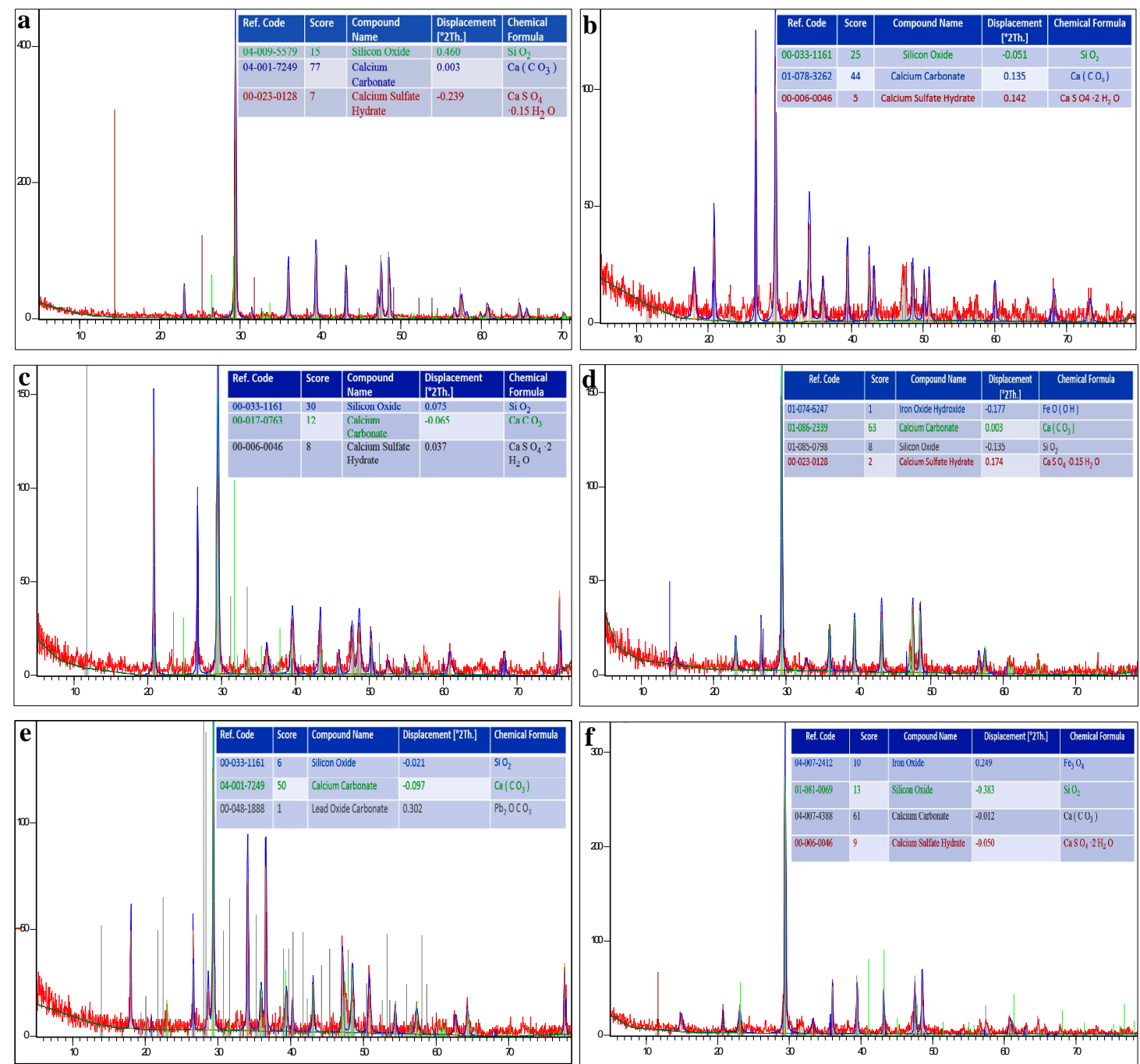

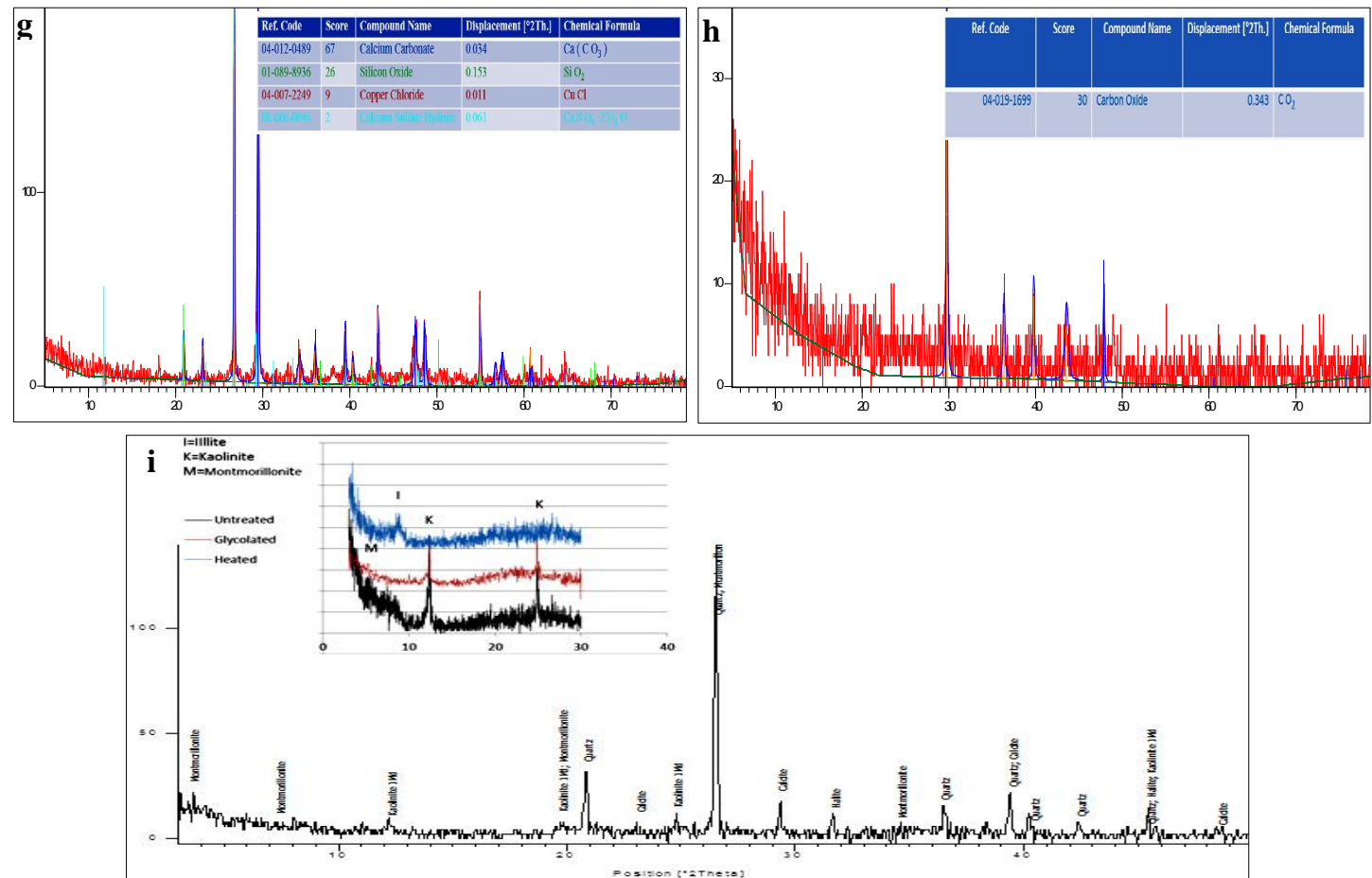

Figure (3) shows XRD patterns of $\underline{\mathbf{a}}$. the plaster layer, $\underline{\mathbf{b}}$. fine layer, $\underline{\mathbf{c}}$. rough layer, $\underline{\mathbf{d}}$. yellow pigment, e. white pigment, $\underline{\mathbf{f}}$. red pigment, g. green pigment, $\underline{\mathbf{h}}$. black pigment, i. support sample

\subsection{SEM- EDX results}

SEM results of the painted surfaces illustrated some aspects of damage, including general weakness, cracks, and flaking of the surface. Moreover, the painting layer is very thin, and the tonal layer looks dry, detached, and uneven due to the extreme temperature, which affects the cohesion of the organic medium, resulting in a drought of the painted layer. Analysis of the ground layers showed the large size of quartz granules used in preparing the first and the second layers. It showed that these layers suffered from drought, as well as some cracks and joints. The plaster layer is very thin. In some places, it is not present or intermittent, fig. (4). The results of the EDX analysis of the plaster layer proved the

presence of $\mathrm{Ca}, \mathrm{Si}$, and $\mathrm{C}$, confirming that less quartz and more calcite were the main components of the coarse ground layers. The presence of $\mathrm{Ca}$ and $\mathrm{C}$ indicated that calcite was the main element in the whitewash or plaster layer, tab. (1-a). In addition, $\mathrm{Fe}, \mathrm{Ca}, \mathrm{Si}$, and $\mathrm{C}$ in the red layer suggested that hematite $\mathrm{Fe}_{2} \mathrm{O}_{3}$ was the main pigment in the red layer, tab. (1-b). Ca, C, and Si showed that calcite $\mathrm{CaCO}_{3}$ was the main pigment in the white layer. In the black layer, C, Ca, and $\mathrm{Si}$ were the main elements of carbon. The analytical results of the green layer indicated that $\mathrm{Cu}, \mathrm{Cl}, \mathrm{Si}, \mathrm{Ca}, \mathrm{Fe}, \mathrm{Al}$, and $\mathrm{C}$ were the main components of copper chloride or green earth; the main component of the green pigment, tab. (1-c).
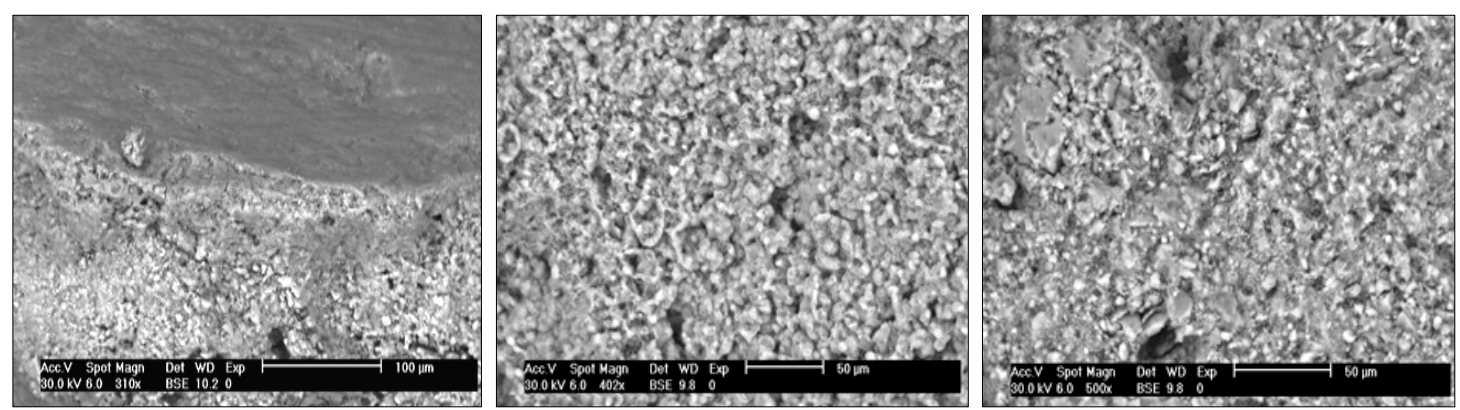

Figure (4) Show SEM micrographs of some deterioration aspects in the painted surfaces and ground layers 
Table (1-a) The results of elemental analysis of the plaster layer

\begin{tabular}{lcccccc}
\hline Element & Wt $\%$ & At $\%$ & K-Ratio & Z & A & F \\
\hline C k & 9.64 & 19.45 & 0.0318 & 1.0648 & 0.3151 & 1.0012 \\
O k & 27.58 & 41.78 & 0.0251 & 1.0320 & 0.0882 & 1.0002 \\
Al k & 0.67 & 0.60 & 0.0027 & 0.9664 & 0.4142 & 1.0074 \\
Si k & 2.00 & 1.73 & 0.0110 & 0.9955 & 0.5465 & 1.0126 \\
P k & 0.71 & 0.55 & 0.0046 & 0.9634 & 0.6541 & 1.0221 \\
S k & 0.64 & 0.49 & 0.0050 & 0.9592 & 0.7613 & 1.0381 \\
Ca k & 58.01 & 35.05 & 0.5601 & 0.9706 & 0.9944 & 1.0004 \\
Fe k & 0.74 & 0.32 & 0.0059 & 0.8955 & 0.8848 & 1.0000 \\
Total & 100.00 & 100.00 & - & - & - & - \\
\hline
\end{tabular}

Table (1-b) Elemental analysis of the red painting layer

\begin{tabular}{lcccccc}
\hline Element & Wt $\%$ & At $\%$ & K-Ratio & Z & A & F \\
\hline C k & 80.14 & 88.32 & 0.4979 & 1.0083 & 0.6160 & 1.0001 \\
O k & 10.30 & 8.52 & 0.0116 & 0.9942 & 0.1135 & 1.0001 \\
Al k & 0.28 & 0.13 & 0.0016 & 0.9316 & 0.6319 & 1.0017 \\
Si k & 0.62 & 0.29 & 0.0046 & 0.9598 & 0.7793 & 1.0025 \\
P k & 0.15 & 0.06 & 0.0012 & 0.9290 & 0.8846 & 1.0045 \\
S k & 0.34 & 0.14 & 0.0031 & 0.9541 & 0.9659 & 1.0073 \\
Ca k & 0.39 & 2.11 & 0.0636 & 0.9258 & 0.0727 & 1.0030 \\
Fe k & 1.79 & 0.43 & 0.0160 & 0.8588 & 0.0364 & 1.0000 \\
Total & 100.00 & 100.00 & - & - & - & - \\
\hline
\end{tabular}

Table (1-c) Elemental analysis of the green painting layer

\begin{tabular}{lcccccc}
\hline Element & Wt \% & At $\%$ & K-Ratio & $\mathbf{Z}$ & $\mathbf{A}$ & F \\
\hline C k & 14.95 & 26.42 & 0.0410 & 1.0410 & 0.2633 & 1.0008 \\
O k & 34.16 & 45.32 & 0.0382 & 1.0263 & 0.1089 & 1.0002 \\
Na k & 0.84 & 0.78 & 0.0017 & 0.9640 & 0.2087 & 1.0017 \\
Mg k & 0.83 & 0.73 & 0.0025 & 0.9893 & 0.2989 & 1.0032 \\
Al k & 1.14 & 0.90 & 0.0046 & 0.9612 & 0.4154 & 1.0058 \\
Si k & 2.03 & 1.54 & 0.0110 & 0.9902 & 0.5421 & 1.0095 \\
P k & 0.49 & 0.33 & 0.0031 & 0.9583 & 0.6493 & 1.0166 \\
S k & 1.60 & 1.06 & 0.0123 & 0.9840 & 0.7601 & 1.0268 \\
CI k & 1.49 & 0.89 & 0.0121 & 0.9426 & 0.8306 & 1.0421 \\
Ca k & 39.51 & 20.93 & 0.3718 & 0.9631 & 0.9751 & 1.0018 \\
Fe k & 2.96 & 1.12 & 0.0244 & 0.8897 & 0.9264 & 1.0000 \\
Total & 100.00 & 100.00 & - & - & - & - \\
\hline
\end{tabular}

\subsection{FTIR results}

The results of the FTIR analysis showed that the Arabic gum was the organic medium in Ain el-Lebekha mural paintings and that the Egyptian artist used the raw materials available in the local environment, such as the Arabic gum as a natural binder found on the trees. The characteristic bands for the identification of the Arabic gum as the main organic binder in the painting samples were $3600-3200 \mathrm{~cm}^{-1} \mathrm{O}-\mathrm{H}$ stretching band, and $300-2800 \mathrm{~cm}^{-1} \mathrm{C}-\mathrm{H}$ stretching bands, as well as others, e.g. $1650 \mathrm{~cm}^{-1}$ $\mathrm{O}-\mathrm{H}$ bending band, and $1480-1300 \mathrm{~cm}^{-1}$ $\mathrm{C}-\mathrm{H}$ bending band, and 1300-900 $\mathrm{cm}^{-1}$ $\mathrm{C}-\mathrm{O}$ stretching bands. They confirmed the Arabic gum bands in the experimental analysis of the archaeological samples, fig. (5) 


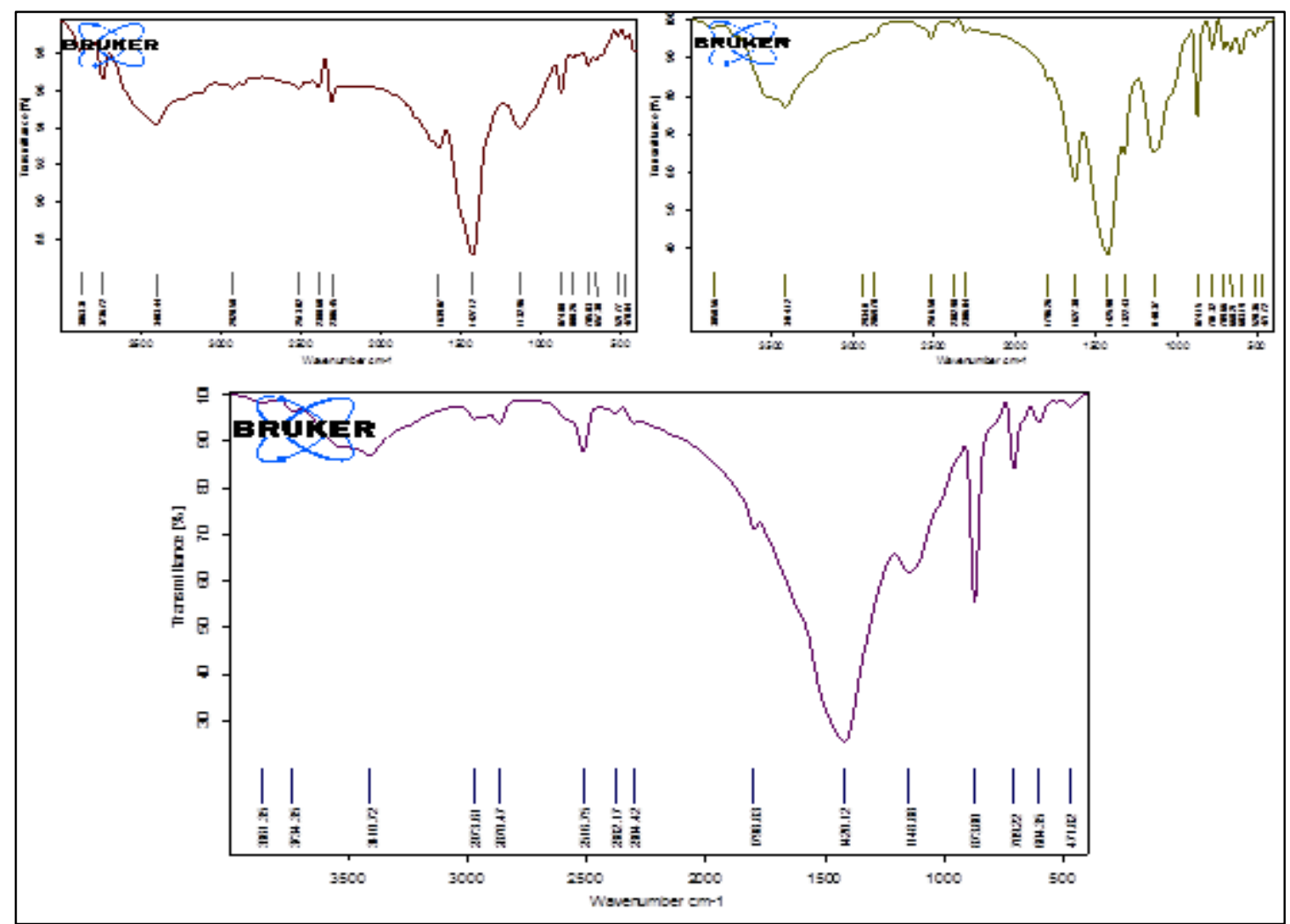

Figure (5) FTIR results showed that the Arabic gum as organic binder.

\section{Discussion}

This study provided abundant and important information about the components, current state, number, and thickness of the mural layers in Ain el-Lebekha Temple. It also showed the extent of damage and the nature of the materials used of each layer (the preparation and plaster layers). The study illustrated the pigments, condition, components, classification, and organic medium of the painting surface. It highlighted the deterioration factors of the mural paintings. The investigations of the mural paintings' layers demonstrated that they consist of two preparation layers (i.e. plaster and painting layers) of different thicknesses $[35,36]$. They were prone to drought, which is evident in the presence of cracks, joints, and gaps, and the use of large granules of quartz, which is available in the local environment. Quartz was added to make the rough preparation layer. The images of the cross-sections of the different layers showed separation, cracks, and drought because the surrounding envir- onment is a desert characterized by high temperatures $[37,38]$. The mural paintings showcasing direct sunlight and high temperatures have directly affected the brittleness and dryness of the gum medium, as well as dryness of the preparation and the plaster layers, causing their separation. SEM images showed that the painting layer is very thin, uneven, and irregular on the surface. Thus, it became weak and was lost. The screening processes illustrated the different mural layers that consist of two layers in addition to the plaster layer that carries the color layer $[39,40]$. The XRD and elemental analysis showed that the painting layers were not thick and suffered from separation. The investigation of some areas of a layer of white plaster showed that it is defined and classified as a component of calcite. The study showed that the pigment materials used in mural paintings were derived from the local environment. For example, hematite was used as a source of red pigment, carbon was used as a source of black 
pigment, and calcite was used for white pigment because lime was common in Egypt at the time. Copper chloride with green earth was used as a source of the green pigment, which was peculiar because malachite, green earth, or Egyptian green were used for paintings. The mud-brick support of the mural paintings was identified by the scientific analysis method which indicated that the main components of the mud-brick are quartz with amounts of calcite and kaolinite with montmorillonite and a type of salt halite found as a trace in the Egyptian soil. In other words, the Egyptian artist made mud brick from local materials and mixed sand with lime and clay minerals (i.e. kaolinite and montmorillonite) [41,42].
The results of the analysis of the organic media confirmed that the Egyptian artist used the Arabic gum technique in these mural paintings in Ain el-Lebekha. The use of calcite or lime in different layers of mural paintings indicated that lime was the most common building materials during the Greco-Roman period. For the definition and classification of the painting technique of mural painting, the infrared absorption method showed the use of the Arabic gum as an organic binder to connect the granules of the pigment materials to each other and to the surface because of its availability in the local environment as a natural binder found on trees $[43,44]$.

\section{Conclusion}

The study proved that mud-brick and limestone as calcite were used as the support of the mural paintings structure in Ain el-Lebekha site. The field observations and examinations and previous analyses indicated that the main components of the mud-brick are quartz, calcite, and kaolinite with montmorillonite and a type of salt halite. Large granules of quartz were added to calcite to make the rough preparation layer, but the ratio of calcite (lime) was greater than quartz in the soft layer. The Arabic gum was used in the different painting surfaces as an organic medium, confirming that the artist used the Arabic Gum technique. All analyses and examinations showed that the murals in Ain el-Lebekha area were prone to various damage factors, especially severe drought, which is evident in their separation, and many small and large cracks. In some places, there is complete separation and the fall of some pieces of murals. Therefore, the immediate treatment plan and future conservation include covering the murals from direct sunlight to reduce or end exposure to sun heat, physical consolidation of the collapsed murals, as well as collection and reinstallation of the pieces and remnants of the fallen mural paintings.

\section{Acknowledgments}

The author would like to thank Dr. Adel Abd El Hamied and Dr. Mustafa Abdelfattah, Restoration Sector, Egyptian Ministry of Antiquities, and Dr. Hamada Sadek, Associate Professor, Faculty of Archaeology, Fayoum University, Egypt.

\section{References}

[1] Wagner, G., (1987). Les oasis d'Egypte à l'époque grecque, romaine et byzantine d'après les documents grecs, $B d E$, Vol. 100, pp: 382-385.

[2] Ikram, S. \& Rossi, C., (2004). An early dynastic Serekh from Kharga Oasis. J. of Egyptian Archaeology, Vol. 90, pp: 211-215.

[3] Salman, A., Howari, F., El-Sankary, M., Wali A. \& Saleh M., (2010). Environmental impact and natural hazards on El-Kharga Oasis monumental sites,

western desert of Egypt, $J$. of African Earth Sciences, Vol. 58, pp: 341353.

[4] Basem, G., Michel, W., Whitehouse, H., Foad, M. \& Marchand, S., (2013). Wall-paintings in a Roman house at ancient Kysis, Kharga Oasis, BIFAO, Vol. 113, pp: 157-182.

[5] Reddé, M., (2004). Douch III. Kysis: fouilles de l'IFAO à Douch oasis de Kharga (1985-1990), DFIFAO, Vol. 42, pp: 1-10. 
[6] Rossi, C. \& Ikram, S., (2004). North Kharga oasis survey 2001-2002, preliminary report: Ain Gib and Qasr el-Sumayra, with contributions by A. Clapham, A. Dunsmore, R. KniselyMarpole, A. Rowe, I. Schacht and N. Warner, MDAIK, Vol. 60, pp: 69-92

[7] Reddé, M., (1999). Sites militaires romains de l'oasis de Kharga, BIFAO, Vol. 99, pp: 377-396.

[8] Ismael, H., (2015). The climate and its impacts on Egyptian civilization heritage, El-Nadura temple in El-Kharga oasis Western desert of Egypt as a case study, Present Environment and Sustainable Development, Vol. 9 (1), pp:5-32.

[9] Naumann, R., (1939). Bauwerke der Oase Khargeh, MDAIK, Vol. 8, pp: 4-7.

[10] Wiseman, M., (2016). The oasis papers 2: Dakhleh oasis project monograph, Reprint ed., Oxbow Books, UK.

[11] Marey, H., (2014). Investigations by Raman microscopy, ESEM and FTIRATR of wall paintings from Qasr el-Ghuieta temple, Kharga oasis, Egypt, Heritage Science, Vol. 2 (18), pp: 2-11.

[12] Abdelaal, Sh., (2012). Application of multi analytical techniques for identification of the mortuary temple of Ramses III, wall paintings compositions. Part one, in: Olszewska-Świetlik, J., Arszyńska, Joanna, M., SzmelterFausek, B. (eds.) Interdisciplinary Research on the Works of Art, Edited Book Chapter, Uniwersytetu Mikołaja Kopernika, Toruń, Poland, pp: 131-149

[13] Calza, C., Anjos M., Mendonçade Souza S., Brancaglion Jr. A. \& Lopesa R., (2007). X-ray micro fluorescence analysis of pigments in decorative paintings from the sarcophagus cartonnage of an Egyptian mummy, Nucl. Instr. and Meth. in Phys. Res. B, Vol. 263 (1), pp: 249-252

[14] Scott, D, Dennis, M., Khandekar, N., Keeney, J., Carson, D. \& Dodd, L., (2003). An Egyptian cartonnage of the Graeco-Roman period, examination and discoveries, Studies in Conservation, Vol. 48 (1), pp: 41-56

[15] Edwards, H., Jorge Villar, S., David, A. \& de Faria, D., (2004). Nondestructive analysis of ancient Egyptian funerary relics by Raman spectroscopic techniques, Analytica Chimica Acta, Vol. 503 (1), pp: 223-233

[16] Abdelaal, Sh., (2011). Identification of painting layers of Sennefer tomb by ion beam analysis, Acta physica Polonica A, Vol.120 (1), pp: 144-148.

[17] Abdelaal, Sh., (2012). Evaluation of biotechnology in the conservation of wall paintings in the mortuary temple of Ramses III, EJARS, Vol. 2 (2), pp: 79-89.

[18] Abdelaal, Sh., Korman, A., Stonert, A., Munnik, F., Turos, A., (2009). Ion beam analysis of ancient Egyptian wall paintings, Vacuum, Vol. 83 (sub. 1), pp: S4-S8

[19] Abdel fatah, M., Kamal, M., Abd El Aal, Sh., (2017). Ptahshepses mural painting and its characterization at Gesr El-Mudir in Saqqara, Egypt, JCHC, Vol. 2, pp.109-125

[20] El Sherbiny, D., Ali, N., Abd El Aal, S., Vallet, J., (2015). A multianalytical approach applied to the archaeometric study of a GrecoRoman decorated wooden panel from Egypt, J. of Ancient Egyptian Interconnections, Vol. 7 (4), pp: $27-$ 37.

[21] Lee, L., Quirke, S., (2000). Painting materials' in ancient Egyptian materials and technology, in: Nicholson, P. \& Shaw, I (ed.) Ancient Egyptian Materials and Technology, Cambridge Univ. Press, NY, pp: 104-121.

[22] Samoilescu, D., Duliu, O., Manea, M. \& Niculescu, G., (2006). FTIR, XRF and optical Microscopy analysis of the painting layer of an early $19^{\text {th }}$ century Icon, Romanian Reports in Physics, Vol. 68 (1), pp: 191-202.

[23] Gebremariam, K., Kvittingen, L. \& Nicholson, D., (2016). Multi-analytical investigation into painting materials 
and techniques: The wall paintings of Abuna Yemata Guh church, Heritage Science, Vol.4 (32), pp:114.

[24] Khandekar, N., (2003.) Preparation of cross-sections from easel paintings., Studies in Conservation, Vol. 48 (sup. 1), pp.52-64

[25] Liritzis, I., \& Polychroniadou, E., (2007). Optical and analytical techniques applied to the Amfissa Cathedral mural paintings made by the Greek artist Spyros Papaloukas (18921957), ArcheoSciences, Vol. 31, pp: 97-112

[26] Pagès-Camagna, S., Laval, E. Vigears, D. \& Duran, A., (2010). Non destructive and in situ analysis of Egyptian wall paintings by X-ray diffraction and X-ray fluorescence portable systems, Applied Physics A, Vol.100 (3), pp: 671-681.

[27] Syta, O., Rozum, K., Choińska, M., Zielińska, D., Żukowska, G., Kijowska, A. \& Wagner, B., (2014). Analytical procedure for characterization of medieval wall-paintings by X-ray fluorescence spectrometry, laser ablation inductively coupled plasma mass spectrometry and Raman spectrosc-opy, Spectrochimica Acta B: Atomic Spectroscopy, Vol.101 (1), pp: 140-148

[28] Robador, M., De Viguerie, L., PérezRodríguez, J., Rousselière, H., Walter, P. \& Castaing, J., (2016). The structure and chemical composition of wall paintings from Islamic and Christian times in the Seville Alcazar, Archaeometry, Vol. 58 (2), pp: 255270

[29] Schmidt, B., Ziemann, M., Pentzien, S., Gabsch, T., Koch, W. \& Krüger, J., (2016). Technical analysis of a Central Asian wall painting detached from a Buddhist cave temple on the northern Silk Road, Studies in Conservation, Vol.61 (2), pp: 113-122.

[30] Piqué, F. \& Verri, G., (2015). Organic materials in wall paintings, Project Report, Getty Conservation Institute, Los Angeles, USA.
[31] Derrick, M., Stulik, D. \& Landry, J., (1999). Infrared Spectroscopy in Conservation Science: Scientific tools for conservation, The Getty Conservation Institute, Los Angeles, USA.

[32] Glavcheva, Z., Yancheva, D. \& Stamboliyska, B., (2014). Development of FTIR spectra database of reference art and archaeological materials, Bulgarian Chemical Communications, Vol.46, (A), pp: 164-169.

[33] Invernizzi, C., Rovetta, T., Licchelli, M. \& Malagodi, M., (2018). Mid and Near-Infrared reflection spectral database of natural organic materials in the cultural heritage field, Int. $J$. of Analytical Chemistry, Vol.1, pp: $1-17$.

[34] Sotiropoulou, S., Papliaka, Z. \& Vaccari, L., (2016). Micro FTIR imaging for the investigation of dete-riorated organic binders in wall pai-nting stratigraphies of different tech-niques and periods, Microchemical J., Vol.124, pp: 559-567

[35] Abo El-Yamin, A., Marey, H. \& Brania, A., (2013). Analytical study of Coptic wall paintings in Egypt, El-Bagawat necropolis, Kharga Oasis: A case study, Periodico di Mineralogia, Vol.82 (1), pp: 25-40.

[36] Cuni, J., (2016). What do we know of Roman wall painting technique? Potential confounding factors in ancient paint media analysis, Heritage Science, Vol. 4 (44), pp.1-13.

[37] Sandu, ICA., Schäfer, S., Magrini, D., Bracci, S. \& Roque, C., (2012). Cross-section and staining-based techniques for investigating organic materials in painted and polychrome works of art: A review, Microscopy and Microanalysis, Vol. 18 (4), pp: 860-875.

[38] Plesters, J., (1956). Cross-sections and chemical analysis of paint samples, Studies in Conservation, Vol. 2 (3), pp: 110-157

[39] Sever Škapin, A., Ropret, P. \& Bukove, P., (2007), Determination 
of pigments in colour layers on walls of some selected historical buildings using optical and scanning electron microscopy, Materials Characterization, Vol. 58 (11), pp:1138-1147.

[40] Kaper, O., (2009). Restoring wall paintings of the temple of Tutu, Egyptian Archaeology, Vol. 35, pp: 3-7.

[41] Hedegaard, S., Delbey, T., Brøns, C. \& Rasmussen, K., (2019). Painting the palace of Apries II: Ancient pigments of the reliefs from the palace of Apries, Lower Egypt, Heritage Science, Vol. 7 (54), pp: 1-32.
[42] Abd El-Hafez, M, (2018). Characterization and restoration recommendation of some adobe shrinks at el Bagawat cemetery, Kharaga Oasis, western desert-Egypt, EJARS, Vol.8, (1), pp: 1-13

[43] Bader, N. \& Rashedy, W., (2014). Analytical study of paint layer in mural painting of Krabia School $\left(19^{\text {th }}\right.$ c.), Cairo, Egypt, MAA, Vol. 14 (2), pp: 349-366

[44] Casadio, F., Giangualano, I. \& Piqué, F., (2004). Organic materials in wall paintings: The historical and analytical literature, Studies in Conservation, Vol. 49 (sup. 1), pp.63-80. 